\title{
ANALISIS PERBANDINGAN KOIL PENGAPIAN STANDARD DAN KOIL PENGAPIAN AFTERMARKET TERHADAP KINERJA SEPEDA MOTOR 4 LANGKAH
}

\author{
Yasin Cakra Mukti ${ }^{1}$, Margono Sugeng ${ }^{2}$ \\ Program Studi Teknik Mesin, Institut Sains dan Teknologi Nasional ${ }^{12}$ \\ email $^{1}$ : abim_2605@yahoo.com
}

\begin{abstract}
This study aims to determine the engine performance (torque, power, and air fuel ratio / AFR) with a variation of the Standard and aftermarket Ignition Coil on the Honda Astrea Legenda 100cc motorbike. The research method used is the experimental method and carried out at the rotating speed (rpm) change, namely by turning on the engine and opening the gas $3000 \mathrm{rpm}$ to full throttle. From testing the engine performance, it can be concluded that the greatest power is obtained by using the Aftermarket SGP RM 80 Ignition Coil with a power of a maximum of $6.83 \mathrm{hp}$ at $6100 \mathrm{rpm}$ engine speed. The biggest torque was also obtained by the Aftermarket SGP Ignition Coil RM 80 of $5.89 \mathrm{ft}$ lbs at 6100 rpm engine speed. From AFR testing, it can be concluded that the level of air and fuel ratio (AFR) produced by the aftermarket ignition coil is more fuel efficient based on the Stoichiometric graph. Using this aftermarket ignition coil starts from the AFR 17.66: 1 to 14.50: 1 .
\end{abstract}

Keywords: Motorcycle, ignition coil, Power, Torque, AFR

\section{PENDAHULUAN}

Seiring waktu berjalan, kemampuan performa kendaraan bermotor akan mengalami penurunan performa dari mesin motor tersebut yang diakibatkan karena umur pemakaian, ataupun perilaku kita saat menjalankan kendaraan tersebut. Oleh sebab itu maka perlu adanya solusi baru untuk mengembalikan bahkan meningkatkan performa motor tanpa harus merubah mesin. Salah satu cara meningkatkan performa kendaraan yang dapat dilakukan dengan mudah adalah dengan pengubahan pada bagian pengapian yaitu koil pengapian.

Oleh karena itu perlu dilakukan penelitian lebih lanjut yang bertujuan untuk mengetahui pengaruh variasi koil pengapian terhadap kinerja sepeda motor 4 langkah. Hasil penelitian ini diharapkan dapat memberikan informasi dan pengetahuan kepada masyarakat tentang pengaruh koil pengapian untuk meningkatkan performa mesin standar pabrikan yang lebih tinggi pada sepeda motor serta penggunaan bahan bakar yang optimal.

\section{TINJAUAN PUSTAKA}

Dalam hal ini perlu diketahui dasar dasar teori motor bakar serta sistem pengapian yang digunakan oleh sepeda motor 4 langkah, penjelasan mengenai jenis koil pengapian serta teori daya, torsi, dan AFR.

\section{Pengertian Motor Bakar}

Motor bakar adalah motor penggerak mula yang pada prinsipnya adalah sebuah alat yang mengubah energi kimia menjadi energi panas dan diubah ke energi mekanis. Energi panas dengan tekanan yang sangat tinggi, membuat volume di ruang bakar menjadi terekspansi yang mengakibatkan terdorongnya piston. Dorongan piston ini menggerakkann komponen-komponen lain yang mengasilkan energi mekanis.

\section{Prinsip Kerja Mesin Bensin 4 Langkah}

Mesin bensin 4 langkah termasuk sebagai motor bakar. Motor bakar merupakan salah satu jenis mesin konversi energi yang banyak dipakai sebagai penggerak kendaran otomotif atau sebagai penggerak peralatan industri. Dengan memanfaatkan energi kalor dari proses pembakaran menjadi energi mekanik. Menurut Arismunandar (2011), prinsip kerja mesin bensin 4 langkah dapat dijelaskan sebagai berikut: (1) Langkah isap (Intake), (2) Langkah Kompresi (Compression), (3) Langkah Pembakaran (Combustion), dan (4) Langkah buang (Exhaust)

\section{Siklus Otto}

Pada siklus otto atau siklus volume konstan proses pembakaran terjadi pada volume konstan. Adapun langkah dalam siklus otto yaitu gerakan piston dari titik puncak (TMA = titik mati atas) ke posisi bawah $(\mathrm{TMB}=$ titik mati bawah) dalam 
silinder (Arismunandar:2011). Diagram P-V siklus otto dapat dilihat pada Gambar 2.1 :
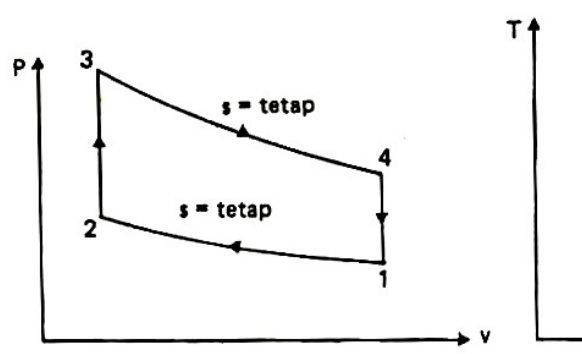

Gambar 2.1 Diagram P-V dan T-S pada siklus otto (Sumber : Otto $p$-v diagram)

Proses siklus otto sebagai berikut:

Proses 0 - 1 Merupakan langkah hisap bahan bakar dimana piston mulai bergerak dari TMA menuju ke TMB dengan posisi katup hisap terbuka dan katup buang tertutup. Akibat dari langkah piston turun ini maka campuran udara bahan bakar akan terhisap, prosesnya terjadi secara isotermis.

Proses 1 - 2 Merupakan langkah kompresi dimana piston bergerak ke atas lagi menuju TMA setelah melakukan langkah hisap dengan posisi katup hisap dan katup buang tertutup. Langkah ini akan menaikkan tekanan pada ruang bakar yang terisi campuran udara dan bahan bakar menjadi naik, prosesnya terjadi secara adiabatik.

Proses 2 - 3 Merupakan proses pembakaran bahan bakar dimana proses ini terjadi sesaat sebelum akhir dari proses kompresi. Campuran bahan bakar dengan udara yang telah terkompresi mulai terbakar akibat percikan api oleh busi. Akibat proses pembakaran ini maka tekanan dan temperatur di ruang bakar menjadi naik tinggi, prosesnya terjadi secara isovolume/isokhorik.

Proses 3-4 Merupakan langkah kerja dimana piston akan bergerak menuju titik mati bawah akibat dari tekanan yang ditimbulkan proses pembakaran. Pada langkah ini posisi katup hisap dan katup buang masih dalam kondisi tertutup. Selama proses ekspansi ini tekanan dan temperatur mulai turun, prosesnya terjadi secara adiabatik.

Proses 4 - 0 Merupakan langkah buang dimana pada akhir langkah kerja piston, katup buang terbuka dan katup hisap tertutup dan piston bergerak menuju ke TMA membuang gas pembakaran keluar dari silinder, prosesnya terjadi secara isovolume/isokhorik.

Menurut Arismunandar (2011), beberapa rumus untuk nenganalisa sebuah siklus otto sebagai tetgerikut :

1. Proses Kompresi Adiabatis

$\frac{T 2}{T 1}=-s^{(k-1)}$ atau $\frac{P 2}{P 1}=r^{k}$

2. Proses Pembakaran Isokhorik $T 3=T 2+\left(\frac{F \cdot Q}{C V}\right)$ Atau P3 $=$ P2. $\left(\frac{T 3}{T 2}\right)$

3. Proses Ekspansi atau Langkah Kerja $\frac{T 4}{T 3}=r^{(1-k)}$ atau $\frac{P 4}{P 3}=r^{(-k)}$

4. Kerja Siklus

$2 \pi \cdot n \cdot T$

$W=C v[(T 3-T 2)-(T 4-T 1)] \quad$ atau

5. Tekanan Efektif Rata-Rata ( Mean

pme $=\frac{w}{(v 1-v 2)}$ Effective Pressure )

6. Daya Indikasi Motor

$P i=$ pme.n. $i \cdot(V 1-V 2) \cdot z$

$7 . \quad$ Torsi

$T=F x l$

8. Daya

$P=\frac{2 \pi \cdot n \cdot T}{33.000}$

Dimana parameter - parameternya adalah:

$\mathrm{P}=$ tekanan gas $\left(\mathrm{Kg} / \mathrm{m}^{3}\right)$

$\mathrm{T}=$ Temperatur suhu $(\mathrm{K})$

$\mathrm{V}=$ Volume gas $\left(\mathrm{m}^{3}\right)$

$\mathrm{Cv}=$ Panas Jenis gas pada volume tetap $(\mathrm{KJ} / \mathrm{Kg})$

$\mathrm{K}=$ Rasio panas jenis gas $(\mathrm{Cp} / \mathrm{Cv})$

$\mathrm{F}=$ Rasio Bahan bakar atau udara

$\mathrm{Q}=$ Nilai panas bahan bakar $(\mathrm{Kj} / \mathrm{Kg})$

$\mathrm{W}=$ Kerja / Usaha ( Joule )

$\mathrm{n}=$ Putaran mesin per detik (rps)

$\mathrm{i}=$ Indeks pengali $\mathrm{i}=1$ untuk 2 tak , dan $\mathrm{i}=0.5$

$\mathrm{z}=$ jumlah silinder untuk 4 tak

$T=$ Torsi $(\mathrm{ft} . \mathrm{lb})$

$\mathrm{P}=$ Daya $(\mathrm{hp})$

$1 \mathrm{hp}=33.000 \mathrm{ft} . \mathrm{lb} / \mathrm{menit}$

Contoh perhitungan yang menghasilkan nilai torsi pada tabel 4.1 kolom pertama sebagai berikut :

$$
\begin{aligned}
& P=\frac{2 \pi \cdot n \cdot T}{33.000} \\
& T=\frac{33.000 \cdot P}{2 \pi \cdot n}
\end{aligned}
$$




$$
T=\frac{33.000 \times 2,65}{2 \times 3,14 \times 4500}=1,70(f t . l b)
$$

\section{Sistem Pengapian}

Sistem pengapian berfungsi untuk membangkitkan bunga api yang dapat membakar campuran bahan bakar-udara di dalam silinder (Toyota, 1994). Menurut Jama dan Wagino (2008b) hal-hal yang diperlukan pada sistem pengapian agar berfungsi optimal, sebagai berikut:

1. Loncatan bunga api yang kuat

2. Saat pengapian yang tepat

3. Kekuatan yang cukup

\section{Koil Pengapian}

Koil pengapian merubah sumber tegangan rendah dari baterai 12 Volt menjadi tegangan tinggi ribuan volt yang diperlukan untuk menghasilkan loncatan bunga api yang kuat pada celah busi dalam sistem pengapian (Jama \& Wagino : 2008b). Jadi koil pengapian hanya dapat merubah tegangan dari baterai 12 Volt menjadi tegangan tinggi 10000 Volt, prinsipnya sama seperti transformator. Transformator itu sendiri ialah alat untuk merubah tegangan dalam nilai lebih tinggi "step up" atau rendah "step down" pada arus listrik bolak balik atau arus putar (Kokelaar : 1978).

\section{Koil Standard}

Koil standard merupakan koil original bawaan dari produsen motor. Koil ini mentransformasikan tegangan baterai 12 Volt menjadi tegangan tinggi lebih 5000 Volt (Tjatur:2013). Hasil pengukuran koil standard motor Honda Astrea Legenda memiliki kumparan primer sebanyak 56 lilitan dengan diameter kawat tembaga 0,6 mm. Tahanan kumparan primer koil pengapian $1,1 \Omega$, sedangkan kumparan sekunder sebanyak 6000 lilitan dengan diameter kawat tembaga 0,06 mm. Tahanan kumparan sekunder sebesar 10,05 $\mathrm{K} \Omega$. Output tegangan tertinggi pada putaran mesin 1500 RPM mencapai 10,2 KV.

\section{Koil Aftermarket}

Menurut Jama \& Wagino (2008b) koil tersebut menaikkan tegangan tinggi mencapai lebih 10 KV. Menurut Oetomo dkk (2014) perbedaan antara koil standard dan koil aftermarket yaitu kumparan primer dan sekunder pada koil aftermarket lebih lebih banyak daripada koil standard. Hal ini yang menyebabkan tegangan yang dihasilkan koil aftermarket lebih besar dibandingkan koil standard.

Hasil pengukuran koil Aftermarket RM 80 kumparan primer memiliki kumparan primer sebanyak 86 lilitan dengan diameter $0,08 \mathrm{~mm}$. Sedangkan kumparan sekunder sebanyak 8000 lilitan dengan diameter kawat tembaga 0,08 $\mathrm{mm}$. Tahanan kumparan primer $0,1 \Omega$ dan tahanan kumparan sekunder 8,73 $\mathrm{K} \Omega$. Output tegangan tertinggi pada putaran mesin 1500 RPM mencapai $20 \mathrm{KV}$.

\section{Parameter Unjuk Kerja Mesin Menggunakan Dynamometer}

Dynamometer adalah alat untuk menghitung torsi dan daya maksimal pada mesin dengan putaran mesin (rpm) tertentu, berdasarkan prinsip kerjanya, dynamometer dibagi menjadi beberapa bagian, yaitu brake based dynamometer dan inertia dynamometer, yang membedakan antara keduanya adalah pada media yang digunakan untuk mengkalibrasi putaran roller dynamometer dengan putaran mesin, yang nantinya dikalkulasi kedalam software, pada Inertia Dynamometer, gaya inersia dari roller menjadi acuan dalam kalibrasi.

Pada pengujian unjuk kerja mesin sepeda motor menggunakan jenis Chassis dynamometer, Chassis dynamometer yang digunakan adalah DynoJet 250i. Dalam unjuk kerja mesin terdapat beberapa parameter utama yang perlu diperhatikan, parameter tersebut merupakan pengaruh dari beberapa kondisi, parameter unjuk kerja meliputi :

A. Torsi (Torque) ft.lb,

Torsi adalah perkalian antara gaya tangensial dengan jarak lengan berputar. Torsi maksimum biasanya digunakan saat kendaraan mau bergerak dan sedang membawa beban berat, biasa disebut akselarasi/tarikan awal.

B. Daya (Power) hp,

Daya efektif didefinisikan sebagai kerja dan sama dengan perkalian antara kecepatan putar (rpm) dengan torsi (Rizal : 2013). Definisi ilmiah dari horse power adalah jumlah energi yang dibutuhkan untuk mengangkat benda seberat 550 lbs setinggi 1 feet dalam waktu 1 detik, dari defiisi ini kita bisa lihat bahwa komponen horse power meliputi tenaga, jarak dan waktu.

C. Air Fuel Ratio (AFR)

Air Fuel Ratio merupakan faktor yang mempengaruhi kesempurnaan proses pembakaran didalam ruang bakar. Merupakan komposisi campuran bensin dan udara. Nilai AFR yang ideal adalah 14,7 artinya campuran terdiri dari 1 bagian bensin dan 14,7 bagian udara biasa (Campuran Stoichiometry).

\section{METODE PENELITIAN}

Metode penelitian ini menggunakan metode pengujian, beberapa langkah yang akan dilakukan sewaktu pengujian kinerja mesin seperti pada gambar 3.1: 


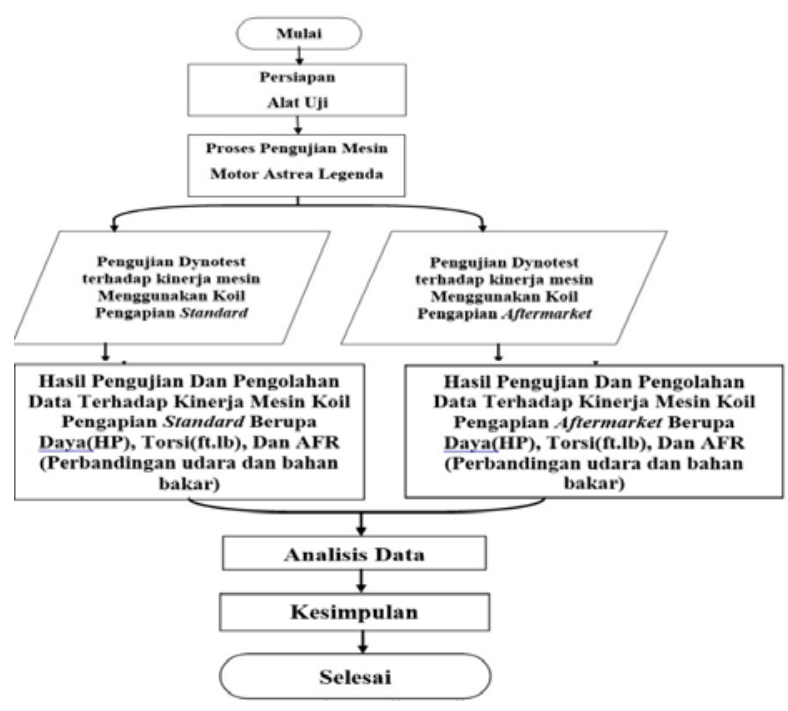

Gambar 3.1 Diagram Alir Pengujian

\section{HASIL ANALISIS DAN PEMBAHASAN}

Dari hasil pengujian pada sepeda motor bensin 4 langkah didapatkan parameter-parameter unjuk kerja mesin berdasarkan penggunaan koil pengapian standard dan koil pengapian aftermarket. Dalam kinerja mesin ada beberapa parameter yang diperoleh meliputi Daya (hp), Torsi (ft.lb), Perbandingan udara-bahan bakar (AFR). Dapat dilihat pada gambar 4.1:

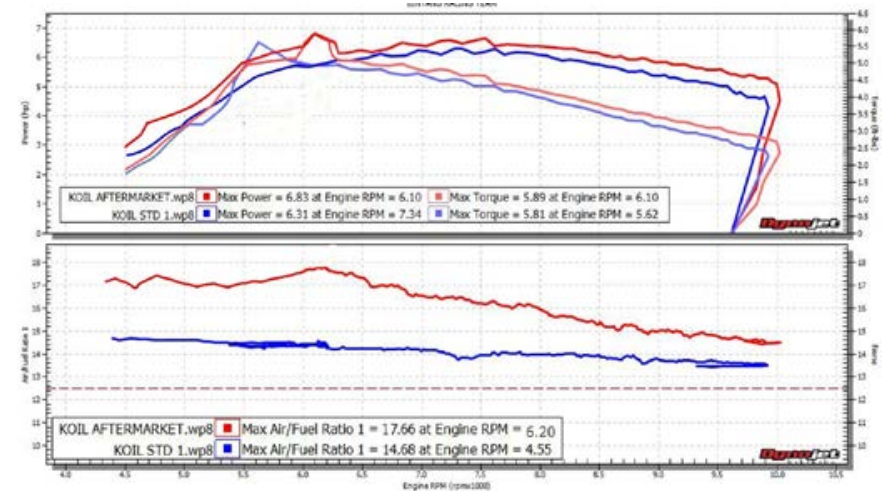

Gambar 4.1 Grafik Hasil Pengujian Daya dan Torsi

Hasil pengujian daya yang dilakukan menggunakan mesin dynamometer menghasilkan daya maksimal 5,80 $h p$ pada putaran mesin 6100 rpm saat menggunakan Koil Pengapian standard dan setelah menggunakan koil pengapian aftermarket daya mesin maksimum naik manjadi 6,83 $h p$ pada $6100 \mathrm{rpm}$. Terjadi peningkatan daya 1,03 hp (14,6\%).

Sedangkan dari hasil pengujian torsi yang dilakukan menggunakan mesin dynamometer, menghasilkan torsi maksimal 5 ft.lb pada putaran mesin 5620 rpm menggunakan koil pengapian standard dan setelah menggunakan koil pengapian aftermarket torsi mesin maksimum naik manjadi 5,89 ft.lb pada $6100 \mathrm{rpm}$. Terjadi peningkatan torsi sebesar 0,89 ft.lb $(11,4 \%)$.
Perbandingan AFR pada pengujian dynamometer mesin motor empat langkah ini tidak terlepas dari kecepatan putaran mesin, tingkat $\mathrm{A} / \mathrm{F}$ dimulai dari 14,68 : 1 sampai 13,60: 1 pada koil pengapian standard dan 17,66: 1 sampai 14,50 : 1 pada koil pengapian aftermarket. Semakin kecil angka $A F R$ maka akan semakin besar pemakaian bahan bakar dan Semakin besar angka $A F R$ maka akan semakin kecil atau sedikit dalam pemakaian bahan bakar.

Hal ini menunjukan bahwa perubahan jenis koil pengapian dapat mempengaruhi daya dan torsi dan AFR yang dihasilkan pada mesin sepeda motor. Pada gambar 4.1, terlihat perubahan nilai lebih besar pada saat menggunakan koil pengapian aftermarket. Ini disebabkan oleh nilai tegangan listrik yang dikeluarkan oleh koil pengapian aftermarket lebih besar dibandingkan menggunakan koil pengapian standard. Sehingga pembakaran yang terjadi di dalam silinder menjadi lebih sempurna dan memungkinkan akan memperingan kerja mesin kendaraan dan berujung pada meningkatnya efisiensi penggunan bahan bakar.

Namun ketika putaran mesin sudah terlalu tinggi daya dan torsi berangsur menurun terlihat dari gambar 4.1 diatas. Ini disebabkan oleh pembukaan katup silinder masuk dan buang yang terlalu cepat pada putaran terlalu tinggi menyebabkan volume ruang bakar menjadi lebih besar. Akibatnya kompresi yang dihasilkan menjadi menurun serta proses pembakaran menjadi kurang sempurna.

\section{KESIMPULAN}

Berdasarkan analisis data dan pembahasan yang telah dilakukan dapat disimpulkan bahwa:

1. Daya yang dihasilkan koil pengapian aftermarket lebih tinggi dibandingkan dengan koil pengapian standard pada setiap putaran mesin. Daya tertinggi yang dihasilkan koil standard daya mencapai 5,80 hp pada putaran mesin $6100 \mathrm{rpm}$, sedangkan menggunakan koil pengapian aftermarket mencapai 6,83 hp pada putaran mesin $6100 \mathrm{rpm}$. Sehingga perubahan tertinggi mencapai $1,03 h p$ $(14,2 \%)$.

2. Torsi yang dihasilkan koil pengapian aftermarket lebih tinggi dibandingkan dengan koil pengapian standard. Torsi tertinggi yang dihasilkan koil standard mencapai $5 \mathrm{ft}$.lb pada putaran mesin 6100 rpm, sedangkan menggunakan koil pengapian aftermarket mencapai 5,89 ft.lb pada putaran mesin 6100 rpm. Sehingga perubahan tertinggi mencapai $0,89 \mathrm{ft.lb}(11,4 \%)$.

3. Tingkat perbandingan udara dan bahan bakar $(A F R)$ yang dihasilkan koil pengapian aftermarket lebih tinggi dibandingkan dengan 
koil pengapian standard. Tingkat AFR dimulai dari 14,68: 1 sampai 13,60: 1 pada koil pengapian standard dan 17,66: 1 sampai 14,50 : 1 pada koil pengapian aftermarket. Sehingga pemakaian bahan bakar lebih irit menggunakan koil pengapian aftermarket berdasarkan grafik Stoichiometric.

\section{DAFTAR PUSTAKA}

Wiranto, Arismunandar. Penggerak Motor Bakar Torak, Edisi 5, Penerbit ITB, Bandung, 2011.

Jama, J dan Wagino. 2008a. Teknik Sepeda Motor Jilid 1. Jakarta: Direktorat Pembinaan Sekolah Menengah Kejuruan, Direktorat Jenderal Manajemen Pendidikan Dasar dan Menengah, Departemen Pendidikan Nasional. 